\title{
A Sun Safety Pilot Program Using a Tanning Myths-Focused Video Contest for Utah Adolescents: Cross-sectional Analysis
}

Amanda Truong ${ }^{1}, \mathrm{PhD}$; Brayden Forbes ${ }^{2}, \mathrm{MD}$; Mingyuan Zhang ${ }^{3}, \mathrm{MSc}$; Molly McFadden ${ }^{4}, \mathrm{MSc}$; Stephanie Klein ${ }^{5}$, MD

${ }^{1}$ Department of Oncological Sciences, University of Utah, Salt Lake City, UT, United States

${ }^{2}$ Division of Dermatology, University of Arizona, Tucson, AZ, United States

${ }^{3}$ Department of Population Health Sciences, University of Utah, Salt Lake City, UT, United States

${ }^{4}$ Department of Internal Medicine, University of Utah, Salt Lake City, UT, United States

${ }^{5}$ Department of Dermatology, University of Utah, Salt Lake City, UT, United States

\section{Corresponding Author:}

Stephanie Klein, MD

Department of Dermatology

University of Utah

30 N 1900 E

Salt Lake City, UT,

United States

Phone: 18015816465

Email: stephanie.klein@hsc.utah.edu

\section{Abstract}

Background: Adolescents are susceptible to excessive ultraviolet exposure due to intentional tanning, outdoor lifestyles, and poor sunscreen adherence. As skin cancer incidence continues to rise in the United States, effective and focused interventions are needed to encourage photoprotective behaviors.

Objective: This study seeks to determine poor photoprotective behavior risk factors in adolescents residing in Utah and whether video contest participants have increased sun-protective knowledge and intentions.

Methods: In this cross-sectional study, we surveyed Utah high school students ( $n=20)$ who participated in a tanning myths-themed public service announcement video contest. A control cohort of students who did not participate in the video contest were also surveyed $(n=89)$. Demographics, sun exposure history, intentions to tan, and intentions to use sunscreen were documented. Knowledge of tanning myths was assessed with a 7-question sun safety quiz.

Results: The survey response rate was 93.2\% (109/117). Two-thirds reported at least one sunburn, and 47.7\% (52/109) reported intentional tanning within the past 2 years. Higher tanning intentions were associated with a personal $(P<.001)$, family $(P=.001)$, and peer $(P<.001)$ history of tanning. Video contest participants had higher sun safety quiz scores $(P<.001)$ and higher sunscreen use intentions $(P=.01)$, but did not have decreased tanning intentions $(P=.47)$ compared to non-video contest participants. Hispanic and Black students were less likely to participate in the video contest $(P<.001$ and $P=.04$, respectively). In a comparison of White students to students of color, there were no differences in sun exposure history, but students of color had lower sun safety knowledge $(P=.01)$ and lower sunscreen use intention $(P=.02)$.

Conclusions: Sun safety educational disparities exist, and targeted efforts are needed to encourage photoprotective behaviors in high-risk populations. Our findings suggest that video contest participation may encourage sunscreen use and sun protection awareness.

(JMIR Dermatol 2021;4(1):e20192) doi: $10.2196 / 20192$

\section{KEYWORDS}

prevention; sun protection; questionnaire; photoprotection; experiential learning; teenager; safety; pilot; video; cross-sectional; adolescent; young adult; behavior; risk; knowledge; intention 


\section{Introduction}

\section{Background}

The incidence of skin cancer has been increasing for the past several decades in the United States [1-3]. The state of Utah has one of the nation's highest skin cancer incidence rates and the highest rate of incidence and death of melanoma, the deadliest type of skin cancer [4]. It has been well established that ultraviolet exposure is a modifiable risk factor for melanoma and nonmelanoma skin cancers [5]. Because adolescents are generally exposed to high amounts of UV radiation from intentional tanning, they are an important target population for skin cancer prevention programming [6].

The most efficacious sun protection programs have been shown to involve children and include active individual participation [7]. Building on this concept, while specifically addressing an adolescent population, we designed and sponsored an annual statewide contest running from 2015 to 2018, in which Utah teenagers voluntarily created 1-minute public service announcement) videos debunking tanning myths. Between 3 and 10 finalists and their families attended a celebratory event at the University of Utah Department of Dermatology each year where their public service announcement videos were viewed, students' achievements were recognized, and the importance of sun-protective behaviors, particularly in Utah, was stressed.

In this study, a cohort of adolescents from high schools who participated in the video contest and a cohort of adolescents from the same high schools who did not participate were electronically surveyed about tanning intentions on sun-protective behaviors and understanding of tanning myths. We sought to identify the demographics and risk factors associated with increased tanning intentions and decreased sunscreen use intentions. We hypothesized that video contest participants would have increased sun-protective intentions and knowledge compared to those who did not participate in the video contest.

\section{Methods}

\section{Recruitment}

This study was approved by the institutional review board at the University of Utah (institutional review board no. 00085420). In June 2018, all students $(\mathrm{n}=22)$ who participated in the video contest between 2015 and 2018 were emailed an anonymous closed survey eliciting demographic information, sun exposure history prior to video contest participation, and the intention to tan or use sunscreen in the future. A 7-question true-or-false knowledge quiz consisting of 5 tanning myths (false) and 2 skin cancer facts (true) was also included. The score was calculated from the quiz to evaluate the tanning myths knowledge of participants by assigning 1 point for each correct answer. A convenience sample of 95 non-video contest participants attending the same high schools were invited to complete the same electronic survey. These participants were recruited at tabling events during 3 lunch time hours and were asked to complete anonymous surveys on tablets or laptop computers provided by the research team. Participants in both groups were given a US $\$ 5$ gift card or a candy bar for completing the survey.

\section{Statistical Analysis}

Tanning intentions were calculated based on participant responses for questions asking likelihood to tan in the future. High tanning intentions corresponded to responses "very likely" or "extremely likely". Medium tanning intentions corresponded to "moderately likely" or "slightly likely" responses, and low tanning intentions corresponded to a "not likely" response. For sunscreen use intentions, answers for likelihood to use sunscreen in the future included "always" or "most of the time" for high intentions, "sometimes" and "rarely" for medium intentions, and "never" for low intentions.

For participant characteristics, we report descriptive statistics as medians (IQR) or frequencies (percentages). To assess the efficacy of the video contest and evaluate the factors associated with knowledge of tanning myths and tanning intentions, we used chi-square tests for categorical variables and Wilcoxon rank sum tests for continuous variables. If numbers were sparse, Fisher exact tests were performed for categorical variables, and the exact version of the Wilcoxon rank sum tests were performed for continuous variables. To compare race demographics, each was compared to the total of each category (ie, White vs. people of color, Hispanic vs. non-Hispanic etc). Results were considered statistically significant if the 2 -sided $P$ values were less than .05 . All tests were performed using $\mathrm{R}$ studio version 1.0.143.

\section{Results}

In total, 109 participants completed the survey (20 video contest participants and 89 non-video contest participants), with a survey response rate of $93.2 \%$ (109/117). Approximately half of the survey respondents were male. Self-identified race included White (51/109, 46.8\%), Hispanic (36/109, 33.0\%), Asian or Pacific islander $(18 / 109,16.5 \%)$, Black or African American (16/109, 14.7\%), Native American (2/109, 1.8\%), and other $(8 / 109,7.3 \%)$. Furthermore, $39.4 \%$ (43/109) of respondents reported having 1 sunburn in the past 2 years, and $26.6 \%(29 / 109)$ reported having at least two or more sunburns in the past 2 years. Almost half (52/109) had a history of intentional tanning, $22.9 \%$ (25/109) had family members that tan, $45.9 \%$ (50/109) had friends who tan, and 26.6\% (29/109) had a family history of skin cancer. In the comparison of video contest and non-video contest participants, White students were more likely to participate in the video contest $(P<.001)$, whereas Hispanic and Black students were less likely to participate in the video contest $(P<.001$ and $P=.04$, respectively; Table 1$)$. 
Table 1. Participant demographics and tanning history comparing video contest $(n=20)$ and non-video contest ( $\mathrm{n}=89)$ participants.

\begin{tabular}{|c|c|c|c|c|}
\hline \multirow[t]{3}{*}{ Characteristic } & \multicolumn{3}{|c|}{ Video contest participant } & \multirow[t]{3}{*}{$P$ value } \\
\hline & & & & \\
\hline & $(\mathrm{N}=109)$ & $(n=20)$ & $(\mathrm{n}=89)$ & \\
\hline Gender, n (\%) & & & & .85 \\
\hline Male & $62(56.9)$ & $11(55)$ & $51(57)$ & \\
\hline \multicolumn{5}{|l|}{ Race $^{\mathbf{a}}, \mathbf{n}(\%)$} \\
\hline White & $51(46.8)$ & $17(85)$ & $34(38)$ & $<.001^{\mathrm{b}}$ \\
\hline Hispanic & $36(33.0)$ & $0(0)$ & $36(40)$ & $<001^{\mathrm{b}}$ \\
\hline Black/African American & $16(14.7)$ & $0(0)$ & $16(18)$ & $.04^{\mathrm{bc}}$ \\
\hline Native American/American Indian & $2(1.8)$ & $0(0)$ & $2(2)$ & $>.99^{\mathrm{c}}$ \\
\hline Asian/Pacific Islander & $18(16.5)$ & $4(20)$ & $14(16)$ & $.74^{\mathrm{c}}$ \\
\hline Other & $8(7.3)$ & $0(0)$ & $8(9)$ & $.35^{\mathrm{c}}$ \\
\hline Sunburn in the past 2 years, n (\%) & & & & .81 \\
\hline More than once & $29(26.6)$ & $5(25)$ & $24(27)$ & \\
\hline Once & $43(39.5)$ & $7(35)$ & $36(40)$ & \\
\hline None & $37(33.9)$ & $8(40)$ & $29(33)$ & \\
\hline Personal history of tanning, n (\%) & & & & .79 \\
\hline Yes & $52(47.7)$ & $9(45)$ & $43(48)$ & \\
\hline Yes & $25(22.9)$ & $6(30)$ & $19(21)$ & \\
\hline No & $84(77.1)$ & $14(70)$ & $70(79)$ & \\
\hline Friends that tan, $\mathrm{n}(\%)$ & & & & .68 \\
\hline Yes & $50(45.9)$ & $10(50)$ & $40(45)$ & \\
\hline No & $59(54.1)$ & $10(50)$ & $49(55)$ & \\
\hline Family history of skin cancer, n (\%) & & & & .13 \\
\hline Yes & $29(26.6)$ & $8(40)$ & $21(27)$ & \\
\hline No & $80(73.4)$ & $12(60)$ & $68(76)$ & \\
\hline Sun safety education in class, $n(\%)$ & & & & .46 \\
\hline Yes & $54(49.5)$ & $8(40)$ & $46(52)$ & \\
\hline No & $55(50.5)$ & $12(60)$ & $43(48)$ & \\
\hline
\end{tabular}

${ }^{\mathrm{a}}$ For race, participants were allowed to pick more than one response.

${ }^{\mathrm{b}}$ Italics indicate value is statistically significant.

${ }^{\mathrm{c}}$ Fisher exact test was used.

Although knowledge of skin cancer facts did not differ between video contest and non-video contest participants $(P=.14$ and $P=.11$, respectively), video contest participants were more likely to correctly identify 2 tanning myths: "A base tan protects you against getting a sunburn" $(P=.02)$ and "There is no need for sun protection on cloudy or cold days" ( $P=.04$; Table 2$)$. Overall, video contest participants had a higher total knowledge quiz score compared to non-video contest participants $(P<.001$; Table 3). Furthermore, quiz scores were not significantly different when students who had prior sun safety classroom education, a history of tanning, or gender or family history of skin cancer were compared to those who did not, but higher quiz scores were associated with high sunscreen intentions $(P=.01$; Tables 3 and 4$)$. 
Table 2. Number of participants answering knowledge quiz questions correctly comparing video contest $(n=20)$ and non-video contest $(n=89)$ participants. Skin cancer facts were used as control questions.

\begin{tabular}{|c|c|c|c|}
\hline \multirow[t]{2}{*}{ Quiz items by correct answers } & \multicolumn{2}{|c|}{ Video contest participant } & \multirow[t]{2}{*}{$P$ value } \\
\hline & Yes $(n=20)$ & No $(n=89)$ & \\
\hline \multicolumn{4}{|l|}{ Tanning myth (false), n (\%) } \\
\hline A "base tan" protects you against getting a sunburn & $19(95)$ & $62(70)$ & $.02^{\mathrm{a}}$ \\
\hline Tanning beds are a safe way to tan & $20(100)$ & $75(84)$ & .07 \\
\hline There is no need for sun protection on cloudy or cold days & $20(100)$ & $72(81)$ & $.04^{a}$ \\
\hline A fake (spray-on or lotion) tan will protect me from the sun & $20(100)$ & $76(85)$ & .12 \\
\hline Only old people get skin cancer & $20(100)$ & $80(90)$ & .21 \\
\hline \multicolumn{4}{|l|}{ Skin cancer fact (true), $\mathrm{n}(\%)$} \\
\hline Utah has one of the highest rates of skin cancer in the country & $13(65)$ & $41(46)$ & .14 \\
\hline Skin cancer is the most common type of cancer & $17(85)$ & $57(64)$ & .11 \\
\hline
\end{tabular}

${ }^{\mathrm{a}}$ Italics indicate value is statistically significant.

Table 3. Analysis of median tanning myths and skin cancer facts quiz scores (maximum score 7).

\begin{tabular}{|c|c|c|}
\hline Variable & Score, median (IQR) & $P$ value \\
\hline Video contest participation & & $<0.001^{\mathrm{ab}}$ \\
\hline Yes $(n=20)$ & $7(6-7)$ & \\
\hline No $(n=89)$ & $5(4-6)$ & \\
\hline Sun safety class education & & 0.82 \\
\hline Yes $(n=54)$ & $6(5-6)$ & \\
\hline No $(n=55)$ & $6(5-6.5)$ & \\
\hline History of tanning & & 0.29 \\
\hline Yes $(n=52)$ & $6(5-6)$ & \\
\hline No $(n=57)$ & $5(4-6)$ & \\
\hline Gender & & $0.16^{\mathrm{a}}$ \\
\hline Male $(n=62)$ & $6(4.2-6)$ & \\
\hline Female $(n=47)$ & $6(5-7)$ & \\
\hline \multicolumn{3}{|l|}{ Race } \\
\hline White only $(\mathrm{n}=40)$ & $6(6-7)$ & $<0.001^{\mathrm{ab}}$ \\
\hline People of color $(n=69)$ & $5(4-6)$ & \\
\hline Family history of skin cancer & & $0.34^{\mathrm{a}}$ \\
\hline Yes $(n=29)$ & $6(5-7)$ & \\
\hline No $(n=80)$ & $6(5-6)$ & \\
\hline
\end{tabular}

${ }^{\mathrm{a}}$ Exact version of Wilcoxon rank sum test used.

${ }^{\mathrm{b}}$ Italics indicate value is statistically significant. 
Table 4. Variables associated with future intentions of sunscreen use and tanning.

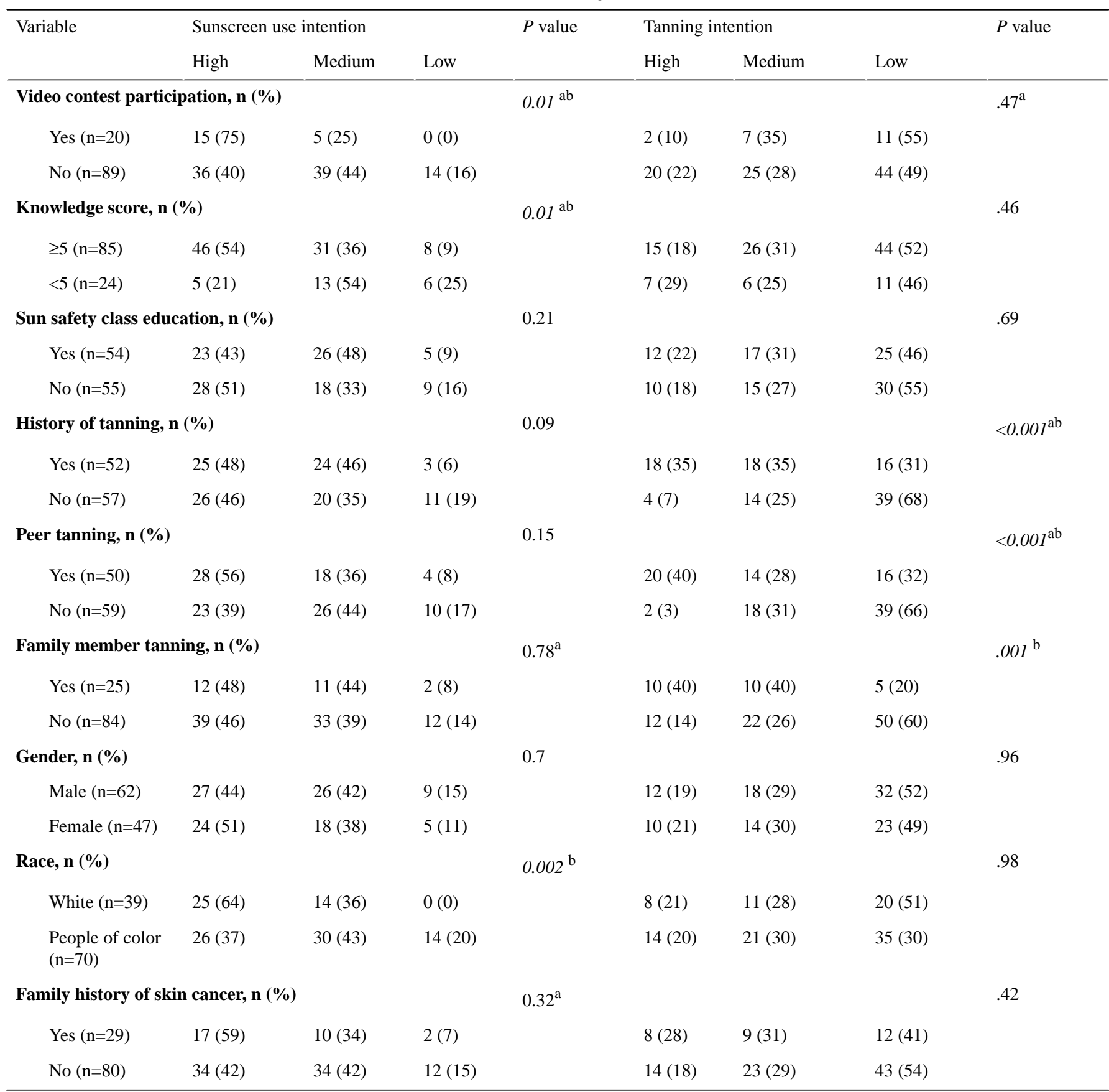

${ }^{\mathrm{a}}$ Fisher exact test was used.

${ }^{\mathrm{b}}$ Italics indicate value is statistically significant.

Analysis of all survey respondents revealed that tanning intentions were significantly higher for those with a history of tanning $(P<.001)$, those who have friends that $\tan (P<.001)$, and those with family members who tan $(P=.001)$. Future intentions to use sunscreen were higher in video contest participants $(P=.01)$ and White students $(P=.002$; Table 4$)$. In addition, White students had higher average knowledge quiz scores compared to students who did not self-identify as only White $(P<.001$; Table 3$)$.
A subsequent analysis of non-video contest participants comparing White students and students of color found no statistical differences in tanning intentions, having family members who tan, having friends who tan, a family history of skin cancer, or a personal history of sunburn. However, students of color had lower tanning myth knowledge scores $(P=.01)$ and reported lower intention to use sunscreen in the future $(P=.02$; Table 5). 
Table 5. Evaluation of tanning knowledge, history, and intentions of non-video contest participants comparing White students ( $\mathrm{n}=23$ ) to students of color $(n=66)$.

\begin{tabular}{|c|c|c|c|c|}
\hline Variable & Total $(\mathrm{N}=89)$ & White $(n=23)$ & People of color $(n=66)$ & $P$ value \\
\hline \multicolumn{5}{|c|}{ Sun safety knowledge, median (IQR) } \\
\hline & $5(4-6)$ & $6(5.5-6)$ & $5(4-6)$ & $.01^{\mathrm{ab}}$ \\
\hline Personal tanning hi & & & & .16 \\
\hline Yes & $43(48)$ & $14(61)$ & $29(44)$ & \\
\hline No & $46(52)$ & $9(39)$ & $37(56)$ & \\
\hline \multicolumn{3}{|c|}{ Family tanning history, $\mathrm{n}(\%)$} & & $>.99^{\mathrm{a}}$ \\
\hline Yes & $19(21)$ & $5(22)$ & $14(21)$ & \\
\hline No & $70(79)$ & $18(78)$ & $52(79)$ & \\
\hline \multicolumn{3}{|c|}{ Peer tanning history, n (\%) } & & .08 \\
\hline Yes & $40(45)$ & $14(61)$ & $26(39)$ & \\
\hline No & $49(55)$ & $9(39)$ & $40(61)$ & \\
\hline \multicolumn{3}{|c|}{ Family history of skin cancer, $n(\%)$} & & .14 \\
\hline Yes & $21(24)$ & $8(35)$ & $13(20)$ & \\
\hline No & $68(76)$ & $15(65)$ & $53(80)$ & \\
\hline \multicolumn{3}{|c|}{ Sunburn in the past 2 years, $n(\%)$} & & .28 \\
\hline More than once & $24(27)$ & $9(39)$ & $15(23)$ & \\
\hline Once & $36(40)$ & $7(30)$ & $29(44)$ & \\
\hline None & $29(33)$ & $7(30)$ & $22(33)$ & \\
\hline \multicolumn{3}{|c|}{ Sunscreen use intention, $\mathbf{n}(\%)$} & & $.02^{\mathrm{bc}}$ \\
\hline High & $36(40)$ & $13(57)$ & $23(35)$ & \\
\hline Medium & $39(44)$ & $10(43)$ & $29(44)$ & \\
\hline Low & $14(16)$ & $0(0)$ & $14(21)$ & \\
\hline \multicolumn{2}{|c|}{ Tanning intention, $\mathbf{n}(\%)$} & & & $.89^{\mathrm{c}}$ \\
\hline High & $20(22)$ & $6(26)$ & $14(21)$ & \\
\hline Medium & $25(28)$ & $6(26)$ & $19(29)$ & \\
\hline Low & $44(49)$ & $11(48)$ & $33(50)$ & \\
\hline
\end{tabular}

${ }^{\mathrm{a}}$ Exact version of Wilcoxon rank sum test was used.

${ }^{b}$ Italics indicate value is statistically significant.

${ }^{\mathrm{c}}$ Fisher exact test was used.

\section{Discussion}

In summary, our study confirms a high percentage of intentional tanning and poor sun-protective behaviors in our adolescent population. In a comparison of those who did and did not participate in a tanning myths-focused video contest, video contest participants had higher sun safety knowledge and higher intentions to use sunscreen, but did not show significant differences in tanning intentions compared to non-video contest participants. In addition, although the video contest was open to all Utah high school students, we had no Black or Hispanic students participate. A subsequent analysis found that students of color had lower sun safety knowledge scores and lower sunscreen use intentions despite having similar sun exposure and tanning histories compared to White students.

We and others have previously shown that sun-protective behaviors decrease as children age [8-10]. Our current study confirms the critical need for continued sun-protective interventions in Utah's adolescent population: two-thirds had at least one sunburn within the past 2 years and nearly half reported intentional outdoor tanning within the past 2 years. Adolescents who report having family members who purposefully tan have displayed similar behavior $[11,12]$. Congruently, those who have parental encouragement to practice sun-protective behaviors are significantly more likely to practice them $[9,13]$. Our study confirms this pattern and another that identifies peer tanning as an important psychosocial factor influencing adolescent tanning behavior $[6,14,15]$. Interventions focused on parental and peer influence may be beneficial for this population. 
Traditional classroom lectures have been shown to be ineffective in promoting photoprotective behavior changes [16-18]. In our cohort, there was no difference in sun safety knowledge or sunscreen and tanning intentions between those that had sun safety education in school versus those that did not. However, our video contest participants were more likely to identify tanning myths resulting in unintentional sun exposure, indicating, "A base tan protects you against getting a sunburn" and "There is no need for sun protection on cloudy or cold days". Video contest participants also reported increased sunscreen use intentions, although they did not have decreased tanning intentions compared to non-video contest participants. Because preintervention knowledge scores were not assessed, we could not determine whether video contest participants had higher baseline knowledge of tanning myths compared to non-video contest participants. Nevertheless, our findings suggest that although skin cancer prevention may be of importance for video contest participants, as implicated by increased sunscreen use intention, the desire to have tanned skin persists. This is in concordance with recent studies that used individualized appearance-based approaches, such as ultraviolet photography and age-enhancing software to promote photoprotective behaviors [10,19-22]. Thus, future studies evaluating experiential learning methods, such as the video contest described herein, in conjunction with an appearance-based model, may show promise with this population.

Of note, adolescent members of underrepresented racial minority groups did not participate in our video contest. Although skin cancer is indeed far less common in people of color, its incidence is rising, and those diagnosed face a poorer prognosis than do White individuals [23]. Poor prognosis is thought to be caused by delay in treatment, which can result from skin cancer misconceptions and socioeconomic factors influencing access of care in people of color, as well as lack of skin cancer education directed towards this population and their providers [24-27]. These factors may also contribute to the lack of participation in our video contest. In particular, students were asked to use their own recording devices, which may discourage those from resource-limited households. Indeed, adolescents who are people of color in our study had both lower tanning myth knowledge scores and decreased sunscreen use intention. However, our findings did not show differences in tanning history, sunburn history, or family history of skin cancer between White students and students of color. These findings underlie the need for targeted skin cancer prevention education that is community- or family-centered for adolescents who are people of color [28-30].

Our study has several limitations including the small sample size surveyed, which reduces the power of our conclusions and renders them ungeneralizable to the adolescent population as a whole. Furthermore, we cannot comment on the efficacy of the video contest in improving knowledge because preintervention tanning knowledge was not assessed in the video contest participants. The video contest may inherently possess a selection bias for those who have a greater understanding of sun safety or access to video recording devices. Thus, the contest may be unappealing to those who are less informed about sun safety or who are less familiar with video production. Follow-up studies are needed to assess retention of sun-protective knowledge and behaviors long term.

In conclusion, adolescents are at high risk for poor sun-protective behaviors. Participating in a public service announcement video contest may promote sunscreen use, but does not reduce tanning intentions. Our findings highlight the need for targeted photoprotective interventions, specifically for those who report high-risk tanning intentions and also those who are people of color.

\section{Acknowledgments}

AT is supported by a National Institutes of Health grant (no. F30CA235964). This investigation was supported by the University of Utah Study Design and Biostatistics Center, with funding in part from the National Center for Research Resources and the National Center for Advancing Translational Sciences, National Institutes of Health (grant no. 8UL1TR000105, formerly no. UL1RR025764).

\section{Conflicts of Interest}

None declared.

\section{References}

1. Lomas A, Leonardi - Bee J, Bath - Hextall F. A systematic review of worldwide incidence of nonmelanoma skin cancer. British Journal of Dermatology 2012 Apr 23;166(5):1069-1080. [doi: 10.1111/j.1365-2133.2012.10830.x]

2. Leiter U, Keim U, Garbe C. Epidemiology of skin cancer: update 2019. Adv Exp Med Biol 2020;1268:123-139. [doi: 10.1007/978-3-030-46227-7 6] [Medline: 32918216]

3. Holman DM, Freeman MB, Shoemaker ML. Trends in melanoma incidence among non-Hispanic whites in the United States, 2005 to 2014. JAMA Dermatol 2018 Mar 01;154(3):361-362 [FREE Full text] [doi: 10.1001/jamadermatol.2017.5541] [Medline: 29387875]

4. U.S. cancer statistics data visualizations tool. Centers for Disease Control and Prevention. 2018 Nov 01. URL: https://www. cdc.gov/cancer/uscs/dataviz/index.htm [accessed 2019-06-19]

5. El Ghissassi F, Baan R, Straif K, Grosse Y, Secretan B, Bouvard V, WHO International Agency for Research on Cancer Monograph Working Group. A review of human carcinogens--part D: radiation. Lancet Oncol 2009 Aug;10(8):751-752. [doi: 10.1016/s1470-2045(09)70213-x] [Medline: 19655431] 
6. Holman DM, Watson M. Correlates of intentional tanning among adolescents in the United States: a systematic review of the literature. J Adolesc Health 2013 May;52(5 Suppl):S52-S59 [FREE Full text] [doi: 10.1016/j.jadohealth.2012.09.021] [Medline: 23601612]

7. Stoebner-Delbarre A, Defez C, Borrel E, Sancho-Garnier H, Sancho-Garnier H, Guillot B. Programmes de prévention des cancers cutanés. Annales de Dermatologie et de Vénéréologie 2005 Sep;132(8-9):641-647. [doi:

10.1016/s0151-9638(05)79411-4] [Medline: 16230913]

8. Görig T, Diehl K, Greinert R, Breitbart E, Schneider S. Prevalence of sun-protective behaviour and intentional sun tanning in German adolescents and adults: results of a nationwide telephone survey. J Eur Acad Dermatol Venereol 2018 Feb;32(2):225-235. [doi: 10.1111/jdv.14376] [Medline: 28573745]

9. Ackermann S, Vuadens A, Levi F, Bulliard J. Sun protective behaviour and sunburn prevalence in primary and secondary schoolchildren in western Switzerland. Swiss Med Wkly 2016;146:w14370 [FREE Full text] [doi: 10.4414/smw.2016.14370] [Medline: 27878788]

10. Weight AB, Forbes BR, Whittier SA, Truong A, Klein SZ. Investigating skin age analysis to reduce tanning intentions among adolescents: A pilot study. Pediatr Dermatol 2018 Dec 05;36(1):50-52. [doi: 10.1111/pde.13734]

11. Cokkinides VE, Weinstock MA, O'Connell MC, Thun MJ. Use of indoor tanning sunlamps by US youth, ages 11-18 years, and by their parent or guardian caregivers: prevalence and correlates. Pediatrics 2002 Jun;109(6):1124-1130. [doi: 10.1542/peds.109.6.1124] [Medline: 12042553]

12. Hoerster KD, Mayer JA, Woodruff SI, Malcarne V, Roesch SC, Clapp E. The influence of parents and peers on adolescent indoor tanning behavior: findings from a multi-city sample. J Am Acad Dermatol 2007 Dec;57(6):990-997 [FREE Full text] [doi: 10.1016/j.jaad.2007.06.007] [Medline: 17658194$]$

13. Miller KA, Huh J, Unger JB, Richardson JL, Allen MW, Peng DH, et al. Patterns of sun protective behaviors among Hispanic children in a skin cancer prevention intervention. Prev Med 2015 Dec;81:303-308 [FREE Full text] [doi: 10.1016/j.ypmed.2015.09.027] [Medline: 26436682]

14. Falzone AE, Brindis CD, Chren M, Junn A, Pagoto S, Wehner M, et al. Teens, tweets, and tanning beds: rethinking the use of social media for skin cancer prevention. Am J Prev Med 2017 Sep;53(3S1):S86-S94 [FREE Full text] [doi: 10.1016/j.amepre.2017.04.027] [Medline: 28818251]

15. Stapleton J, Turrisi R, Hillhouse J. Peer crowd identification and indoor artificial UV tanning behavioral tendencies. J Health Psychol 2008 Oct;13(7):940-945 [FREE Full text] [doi: 10.1177/1359105308095068] [Medline: 18809645]

16. Day AK, Wilson CJ, Hutchinson AD, Roberts RM. The role of skin cancer knowledge in sun-related behaviours: a systematic review. J Health Psychol 2014 Sep;19(9):1143-1162. [doi: 10.1177/1359105313485483] [Medline: 23682066]

17. Geller AC, Shamban J, O'Riordan DL, Slygh C, Kinney JP, Rosenberg S. Raising sun protection and early detection awareness among Florida high schoolers. Pediatr Dermatol 2005;22(2):112-118. [doi: 10.1111/j.1525-1470.2005.22204.x] [Medline: 15804297$]$

18. Miller KA, Langholz BM, Ly T, Harris SC, Richardson JL, Peng DH, et al. SunSmart: evaluation of a pilot school-based sun protection intervention in Hispanic early adolescents. Health Educ Res 2015 Jun;30(3):371-379 [FREE Full text] [doi: 10.1093/her/cyv011] [Medline: 25801103]

19. Dodd LJ, Forshaw MJ. Assessing the efficacy of appearance-focused interventions to prevent skin cancer: a systematic review of the literature. Health Psychology Review 2010 Sep;4(2):93-111. [doi: 10.1080/17437199.2010.485393]

20. Hillhouse J, Turrisi R, Scaglione NM, Cleveland MJ, Baker K, Florence LC. A web-based intervention to reduce indoor tanning motivations in adolescents: a randomized controlled trial. Prev Sci 2017 Feb;18(2):131-140 [FREE Full text] [doi: 10.1007/s11121-016-0698-4] [Medline: 27549602]

21. Brinker TJ, Heckl M, Gatzka M, Heppt MV, Resende Rodrigues H, Schneider S, et al. A skin cancer prevention facial-aging mobile app for secondary schools in Brazil: appearance-focused interventional study. JMIR Mhealth Uhealth 2018 Mar 09;6(3):e60 [FREE Full text] [doi: 10.2196/mhealth.9794] [Medline: 29523502]

22. Brinker TJ, Klode J, Esser S, Schadendorf D. Facial-aging app availability in waiting rooms as a potential opportunity for skin cancer prevention. JAMA Dermatol 2018 Sep 01;154(9):1085-1086 [FREE Full text] [doi:

10.1001/jamadermatol.2018.1907] [Medline: $\underline{\text { 30046805] }}$

23. Gloster HM, Neal K. Skin cancer in skin of color. J Am Acad Dermatol 2006 Nov;55(5):741-60; quiz 761. [doi: 10.1016/j.jaad.2005.08.063] [Medline: 17052479]

24. Agbai ON, Buster K, Sanchez M, Hernandez C, Kundu RV, Chiu M, et al. Skin cancer and photoprotection in people of color: a review and recommendations for physicians and the public. J Am Acad Dermatol 2014 Apr;70(4):748-762. [doi: 10.1016/j.jaad.2013.11.038] [Medline: 24485530]

25. Buchanan Lunsford N, Berktold J, Holman DM, Stein K, Prempeh A, Yerkes A. Skin cancer knowledge, awareness, beliefs and preventive behaviors among black and hispanic men and women. Prev Med Rep 2018 Dec;12:203-209 [FREE Full text] [doi: 10.1016/j.pmedr.2018.09.017] [Medline: 30364862]

26. Ma F, Collado-Mesa F, Hu S, Kirsner RS. Skin cancer awareness and sun protection behaviors in white Hispanic and white non-Hispanic high school students in Miami, Florida. Arch Dermatol 2007 Aug;143(8):983-988. [doi:

10.1001/archderm.143.8.983] [Medline: 17709656] 
27. Coups EJ, Stapleton JL, Hudson SV, Medina-Forrester A, Natale-Pereira A, Goydos JS. Sun protection and exposure behaviors among Hispanic adults in the United States: differences according to acculturation and among Hispanic subgroups. BMC Public Health 2012 Nov 15;12:985 [FREE Full text] [doi: 10.1186/1471-2458-12-985] [Medline: 23153104]

28. Kumar V, Kumar A, Ghosh AK, Samphel R, Yadav R, Yeung D, et al. Enculturating science: Community-centric design of behavior change interactions for accelerating health impact. Semin Perinatol 2015 Aug;39(5):393-415. [doi: 10.1053/j.semperi.2015.06.010] [Medline: 26215599]

29. Alsop K, Thorne H, Sandhu S, Hamilton A, Mintoff C, Christie E, Melbourne Melanoma Project, Australian Ovarian Cancer Study Group (AOCS), Kathleen Cuningham Foundation Consortium for Research into Familial Breast Cancer (kConFab), et al. A community-based model of rapid autopsy in end-stage cancer patients. Nat Biotechnol 2016 Oct;34(10):1010-1014. [doi: 10.1038/nbt.3674] [Medline: 27617737]

30. Dadlani C, Orlow S. Planning for a brighter future: a review of sun protection and barriers to behavioral change in children and adolescents. Dermatol Online J 2008 Sep 15;14(9):1 [FREE Full text] [Medline: 19061583]

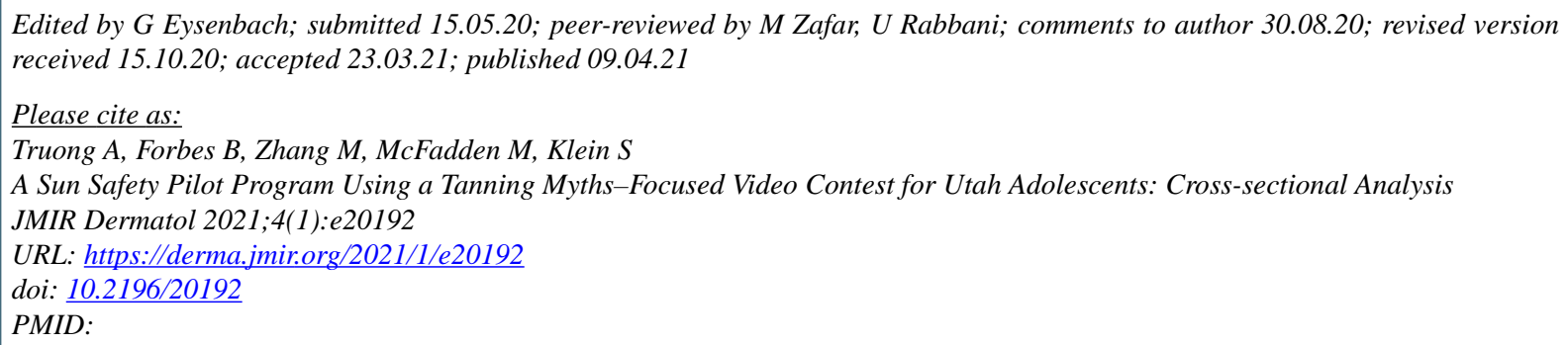

(C)Amanda Truong, Brayden Forbes, Mingyuan Zhang, Molly McFadden, Stephanie Klein. Originally published in JMIR Dermatology (http://derma.jmir.org), 09.04.2021. This is an open-access article distributed under the terms of the Creative Commons Attribution License (https://creativecommons.org/licenses/by/4.0/), which permits unrestricted use, distribution, and reproduction in any medium, provided the original work, first published in JMIR Dermatology Research, is properly cited. The complete bibliographic information, a link to the original publication on http://derma.jmir.org, as well as this copyright and license information must be included. 